\title{
Original Article \\ Bufalin Induces Reactive Oxygen Species Dependent Bax Translocation and Apoptosis in ASTC-a-1 Cells
}

\author{
Lei Sun, ${ }^{1}$ Tongsheng Chen, ${ }^{1}$ Xiaoping Wang, ${ }^{2}$ Yun Chen, ${ }^{3}$ and Xunbin Wei ${ }^{3}$ \\ ${ }^{1}$ MOE Key Laboratory of Laser Life Science \& Institute of Laser Life Science, South China Normal University, \\ Guangzhou 510631, China \\ ${ }^{2}$ Department of Anesthesiology, The First Affiliated Hospital of Jinan University, Guangzhou 510632, China \\ ${ }^{3}$ Institutes of Biomedical Sciences, Fudan University, Shanghai 200032, China \\ Correspondence should be addressed to Tongsheng Chen, chentsh@scnu.edu.cn
}

Received 1 February 2009; Accepted 15 June 2009

Copyright () 2011 Lei Sun et al. This is an open access article distributed under the Creative Commons Attribution License, which permits unrestricted use, distribution, and reproduction in any medium, provided the original work is properly cited.

\begin{abstract}
Bufalin has been shown to induce cancer cell death through apoptotic pathways. However, the molecular mechanisms are not well understood. In this study, we used the confocal fluorescence microscopy (CFM) to monitor the spatio-temporal dynamics of reactive oxygen species (ROS) production, Bax translocation and caspase- 3 activation during bufalin-induced apoptosis in living human lung adenocarcinoma (ASTC-a-1) cells. Bufalin induced ROS production and apoptotic cell death, demonstrated by Hoechst 33258 staining as well as flow cytometry analysis. Bax redistributed from cytosol to mitochondria from 12 to $48 \mathrm{~h}$ after bufalin treatment in living cells expressed with green fluorescent protein Bax. Treatment with the antioxidant $N$-acetyl-cysteine (NAC), a ROS scavenger, inhibited ROS generation and Bax translocation and led to a significant protection against bufalininduced apoptosis. Our results also revealed that bufalin induced a prominent increase of caspase-3 activation blocked potently by NAC. Taken together, bufalin induced ROS-mediated Bax translocation, mitochondrial permeability transition and caspase-3 activation, implying that bufalin induced apoptosis via ROS-dependent mitochondrial death pathway in ASTC-a-1 cells.
\end{abstract}

\section{Introduction}

Apoptosis is a highly regulated and organized cell death process controlling the development and homeostasis of multicellular organisms that occur under a variety of physiological and pathological conditions [1]. It is characterized by a number of well-defined features including cellular morphological change, chromatin condensation, oligonucleosomal DNA cleavage, translocation of phosphatidylserine (PS) from the inner to the outer leaflet of the plasma membrane and activation of a family of cysteine proteases called caspases [2]. Caspases activation is generally considered to be a key hallmark of apoptosis. Caspase-3, an effector caspase, has been implicated in the execution phase of apoptosis [3].

Bax, a death effector of Bcl-2 family, plays an essential role in the mitochondrial pathway of apoptosis $[4,5]$. Bax undergoes a conformational change and translocates from cytosol to the outer mitochondrial membrane in the early step of the apoptotic pathway [4]. Translocation of Bax and Bid to the mitochondria leads to the loss of mitochondrial membrane potential $\left(\Delta \Psi_{m}\right)[4,6-8]$.
Reactive oxygen species (ROS) have been identified as important mediators regulating signal transduction [9]. ROS can induce injury in a variety of mammalian cells $[10,11]$ and play crucial roles in the signaling pathway of drug-induced preconditioning [9]. ROS generation has also been demonstrated following the administration of many mitochondrial-dependent apoptotic stimuli including some chemotherapeutic agents [12]. In many apoptosis models, investigators have reported that ROS generation occurs downstream of the release of cytochrome $c$ from the mitochondria [13]. ROS have been reported to be in-volved in various lung cancer cells apoptosis like lung cancer A549 cells [14] and human non-small cell lung cancer cells (NSCLC) [15]. However, the exact mechanism of ROSmediated apoptosis is still unclear.

Lung cancer is the leading cause of cancer death throughout the world [16]. For therapeutic purposes, lung cancer is generally divided into small-cell lung cancer (SCLC) and non-SCLC (NSCLC) [17], with the latter constituting major populations [18]. Various approaches for lung cancer treatment including induction of differentiation and apoptosis 
have been attempted, but conventional chemotherapy and radiotherapy of lung cancer are still of limited effectiveness, necessitating the development of new treatment strategy [15]. It is of paramount importance to discover novel agents with less severe side effects and drug resistance.

Bufalin has been found to induce cell apoptosis in various types of cancer cells, but the precise molecular mechanism is still unclear. Bufalin is the major digoxin-like immunoreactive component of $\mathrm{Chan}-\mathrm{Su}$, a traditional Chinese medicine obtained from the skin and parotid venom glands of toad [19]. Bufalin exhibit a variety of biological activities, such as cardiotonic, anesthetic, blood pressure stimulation, respiration and antineoplastic activities. In terms of its anti-tumor activities, bufalin has been demonstrated to induce apoptosis in leukemic cells, human hepatocellular carcinoma and prostatic cancer [20-22]. Induction of apoptosis by bufalin in human tumor cells has been reported to associate with a change of intracellular concentration of $\mathrm{Na}^{+}$ions by inhibiting the $\mathrm{Na}^{+}$and $\mathrm{K}^{+}$-ATPase on the cell membrane $[23,24]$.

The fluorescence resonance energy transfer (FRET) technique has been widely used to study protein-protein interactions in living cells $[25,26]$. In order to monitor caspase3 activation in living cells, Miura et al. [25] constructed a FRET probe, SCAT3, which consists of enhanced cyan fluorescent protein (ECFP) as a donor, a mutant of yellow fluorescent protein (Venus) as an acceptor and a linking peptide sequence containing a caspase- 3 cleavage (DEVD) between ECFP and Venus. Activated caspase- 3 cleaves the linker, thus, effectively reduces the FRET [25]. The FRET technique based on SCAT3 has been widely used to monitor the spatio-temporal dynamics of caspase- 3 activation in individual living cells in real time in our previous studies [26].

The purpose of this study was to investigate the molecular mechanism of bufalin-induced apoptosis in human lung adenocarcinoma (ASTC-a-1) cells. In addition to conventional methods, time-lapse fluorescence confocal microscopy (CFM) and emission spectral analysis based on FRET were used to monitor the spatio-temporal dynamics of ROS production, Bax translocation and caspase- 3 activation during bufalin-induced apoptosis in living cells.

\section{Methods}

Bufalin was obtained from Alexis (Lausen, Switzerland). Working solutions were prepared by dissolving the compound in $100 \%$ ethanol before experiment. The final concentration of ethanol was $<0.1 \%$ in all experiments. Lipofectamine 2000 and Mitotracker Red were purchased from Invitrogen (Carlsbad, CA, USA). NAC (ROS scavenger), Rhodamine 123 (Rho123) and Hoechst 33258 were obtained from Sigma (St. Louis, MO, USA). Cell Counting Kit (CCK-8) was purchased from Dojindo (Kumamoto, Japan). Annexin V (FITC) apoptosis detection kit was obtained from Bender Medsystems (Vienna, Austria) and AcDEVD-AFC was purchased from Alexis (Lausen, Switzerland). z-VAD-fmk, a broad spectrum caspase inhibitor, was purchased from BioVision (CA, USA). 2', $7^{\prime}$-Dichlorodihydrofluorescein diacetate (DCFH-DA) was purchased from Wako Ltd (Osaka, Japan). SCAT3 plasmid was kindly provided by Dr. Miura [25].

2.1. Cell Culture and Transfection. ASTC-a-1 cell line was obtained from the Department of Medicine, Jinan University (Guangzhou, China). Dulbecco's modified Eagle's medium (DMEM) was purchased from Gibco (Grand Island, NY, USA). For fluorescence studies, the cells were transferred in 35-mm dish $24-48 \mathrm{~h}$ after transfection. The cell line stably expressing SCAT3 was obtained from our previous studies [26]. All the cells were cultured in DMEM supplemented with $10 \%$ fetal calf serum with $5 \% \mathrm{CO}_{2}$ at $37^{\circ} \mathrm{C}$ in a humidified incubator.

2.2. Cell Viability Assay. Cell viability after treatment with bufalin was measured by the CCK- 8 assay. ASTC-a- 1 cells were suspended at a final concentration of $1 \times 10^{4}$ cells/well and cultured in a 96-well flat-bottomed microplate. After different treatment of cells, CCK-8 $(10 \mu \mathrm{l})$ was added to each well containing $100 \mu \mathrm{l}$ of the culture medium and bufalin mixture, and the plate was incubated for $1 \mathrm{~h}$ at $37^{\circ} \mathrm{C}$. Viable cells were counted by absorbance measurements at $450 \mathrm{~nm}$ using auto-microplate reader (infinite M200, Tecan, Austria). All experiments were performed in triplicate on three separate occasions.

2.3. Cell Apoptosis Detection. Cell apoptosis detection was performed by fluorescence-activated cell sorting (FACS) analysis using a flow cytometer (FCM, Arla BD, USA) with apoptotic cells being annexin $\mathrm{V}$ positive/PI negative. The exposure of PS on the extracellular side of the cell membrane was quantified by annexin V/PI staining. Treated cells in a 6-well plate with a density of $1 \times 10^{6}$ were collected by centrifugation ( $1200 \mathrm{rpm}$ for $3 \mathrm{~min}$ ) and washed by PBS. Then cells were stained with $5 \mu \mathrm{l}$ of annexin V-FITC for $30 \mathrm{~min}$ and $10 \mu \mathrm{l}$ propidium iodide (PI, $10 \mu \mathrm{g} / \mathrm{ml}$ ) for $10 \mathrm{~min}$ at room temperature. After being screened with 300-mesh sieve, cellular DNA was detected by flow cytometry (FCM) and apoptosis rate was computed.

2.4. Morphological Examination for Apoptosis. The cells were grown on the cover slip of a $35-\mathrm{mm}$ chamber. After being treated with bufalin for $48 \mathrm{~h}$ in the absence or presence of $\mathrm{NAC}$ at $37^{\circ} \mathrm{C}$, the cells were washed with PBS three times and incubated with $1-\mu \mathrm{M}$ Hoechst 33258 for $20 \mathrm{~min}$ at room temperature in the dark. The cells were then washed three times with PBS and visualized under a Zeiss fluorescent microscope (Axiovert 200M). The images of Hoechst 33258 were recorded using a digital camera (Nikon, Tokyo, Japan) with $1280 \times 1280$ pixels resolution.

2.5. Confocal Fluorescence Live Monitoring. Fluorescence imaging was performed on a confocal microscope (LSM510/ ConfoCor2, Zeiss, Jena, Germany). All quantitative analyses of the fluorescence images were performed with the Zeiss Rel3.2 image processing software (Zeiss). For time-lapse imaging of ROS, culture dishes were mounted onto the microscope stage equipped with a temperature-controlled 
chamber and was stained with $10-\mu \mathrm{M}$ DCFH-DA in PBS for $15 \mathrm{~min}$ at $37^{\circ} \mathrm{C}$. DCFH-DA was cleaved by intracellular esterases and turned to the highly fluorescent $2^{\prime}, 7^{\prime}$ dichlorodihydrofluorescein (DCF) upon oxidation by ROS. The fluorescence images of green fluorescent protein (GFP) and DCF were excited by a 488-nm laser and fluorescence emission was recorded through a 500-550-nm band-pass filter.

2.6. Mitochondrial Size Determination. The cells were cultivated on a coverslip of a $35-\mathrm{mm}$ chamber. At indicated times after being treated with bufalin, the cells were washed with PBS three times and incubated with $0.1-\mu \mathrm{M}$ Mito-tracker Red for $30 \mathrm{~min}$ at room temperature in the dark. Then the cells were washed three times with PBS and visualized. Mitotracker Red was excited by a 633-nm laser and the emitted light was recorded through a 650-nm long-pass filter. For each condition tested the size of 100-200 mitochondria in at least 50 different cells was measured from three independent experiments.

2.7. Measurement of Mitochondrial Membrane Potential $\left(\Delta \Psi_{m}\right)$. Rho123 was used to evaluate the changes of $\Delta \Psi_{m}$ by FCM. The cells were grown at a density of $1 \times 10^{5}$ cells in 12-well flat-bottomed microtiter plates. After treatment with bufalin for indicated times in the absence or presence of NAC, the cells in 1-ml PBS were stained with $1^{-} \mathrm{M}$ Rho123 for $30 \mathrm{~min}$ in dark at room temperature. The cells were then collected by centrifugation (1200 rpm, $3 \mathrm{~min}$ ), washed with PBS three times and resuspended in 1-ml PBS. Fluorescence emitted from the Rho123 was detected with a flow cytometer (FACS. Arla BD, USA).

2.8. Fluorescence Spectral Analysis Inside Living Cells. ASTCa- 1 cells stably expressing SCAT3 were cultured in the 96well flat-bottomed microplate for $24 \mathrm{~h}$. The cells were then incubated with $0.1-\mu \mathrm{M}$ bufalin for $48 \mathrm{~h}$ and $1-\mu \mathrm{M}$ STS for $12 \mathrm{~h}$ in the presence or absence of $10-\mu \mathrm{M}$ z-VAD-fmk or 5mM NAC. The emission spectra of the SCAT3 were detected by auto-microplate reader (infinite M200, Tecan, Austria). In the meantime, emission spectra of non-transfected cells were obtained as background. The step length of the scanning spectra is $2 \mathrm{~nm}$. The excitation wavelength of SCAT3 was 409-427 nm and the emission fluorescence channel was 454600-nm band-pass.

2.9. Fluorometric Assay for Caspase-3 Activity. For the detection of caspase-3 activity, PBS-washed cell pellets (derived from either the medium or the adherent cells) were resuspended in extract buffer (25-mM HEPES ( $\mathrm{pH} 7.4$ ), 0.1\% TritonX-100, 10\% glycerol, 5-mM DTT, 1-mM phenylmethylsulfonyl fluoride, $10-\mathrm{mg} / \mathrm{ml}$ pepstatin, and $10-\mathrm{mg} / \mathrm{ml}$ Leupeptin) and vortexed vigorously. A $20 \mu \mathrm{l}$ of the extracts (corresponding to $10 \%$ of the sample) were incubated with the caspase-3 fluorogenic substrates Ac-DEVD-AFC at a $100 \mu \mathrm{M}$ final concentration at room temperature. Caspase3 activity was measured continuously by monitoring the release of fluorigenic AFC at $37^{\circ} \mathrm{C}$. The excitation wavelength of AFC was $400 \mathrm{~nm}$ and the emission wavelength was $530 \mathrm{~nm}$ using auto-microplate reader (infinite M200, Tecan, Austria).

2.10. Protein Extraction and Western Blot Analysis. For western blot analysis, the cells were treated with $1-\mu \mathrm{M}$ STS for $12 \mathrm{~h}, 0.1-\mu \mathrm{M}$ bufalin for $48 \mathrm{~h}$ and combined treatment with $0.1-\mu \mathrm{M}$ bufalin and 5-mM NAC for $48 \mathrm{~h}$. Collected cells were washed with cold PBS and lysed in lysis buffer (50-mM Tris- $\mathrm{HCl}, \mathrm{pH}$ 8.0, 150-mM NaCl, 1\% Triton-100, 1-mM PMSF and protease inhibitor cocktail set I). Protein content was quantitated using the Bradford assay. Equivalent amounts of total protein were resolved by $15 \%$ SDS-PAGE and transferred to nitrocellulose membranes (Millipore Co., Billerica, MA, USA) following the conventional protocols. Before being immunoblotted, the membranes were blocked in 5\% non-fat milk in TBST buffer (10-mM Tris $\mathrm{pH} 7.5$, $150-\mathrm{mM} \mathrm{NaCl}, 0.1 \%$ Tween 20 ) for $1 \mathrm{~h}$ at room temperature. The rabbit polyclonal anti-caspase-3 (Cell signaling, Cat. no. 9746) was used at a dilution of 1:1000 for overnight at $4^{\circ} \mathrm{C}$ and secondary anti-rabbit IgG-HRP (Rockland, Gilbertsville, PA, USA) was used at $1: 3000$ for $2 \mathrm{~h}$. Detection was performed using the LI-COR Odyssey Infrared Imaging System (LI-COR, Inc., Lincoln, NE, USA)

2.11. Statistical Analysis. The results are expressed as mean \pm standard deviation (SD). Statistical analysis was performed with SPSS 10.0 software for multiple comparisons. A $P$-value of $<.05$ was considered to be statistically significant.

\section{Results}

3.1. Bufalin-Induced Cell Apoptosis. The effect of bufalin on cell viability was assessed using CCK-8. Our data showed that bufalin induced a dose-dependent cell death (Figure 1(a)). The dose of $0.1-\mu \mathrm{M}$ bulfalin was then adopted in the following experiments for indicated times. To further determine the form of bufalin-induced cell death, we used FCM to analyze the PS alteration and membrane disruption of cells costained with annexin V-FITC and PI after bufalin treatment (Figure 1). The cells treated with STS were analyzed as positive control (Figure 1(c)). We found out that bufalin induced a significant increase in FITC fluorescence (Figures 1(d) and 1(e)), while the PI fluorescence in the Q1 area was almost the same as the control (Figure 1(b)), suggesting that bufalin induced apoptotic cell death.

3.2. ROS Involvement in Bufalin-induced Cell Apoptosis. In order to investigate ROS generation during bufalininduced apoptosis, the ROS-sensitive vital dye DCF was used to detect the production of ROS in real time by CFM. We found out that bufalin induced a marked increase in DCF fluorescence within $30 \mathrm{~min}$, which was inhibited completely by NAC (Figure 2(a)). The dynamics of the DCF fluorescence corresponding to Figure 2(b) were shown in Figure 2(b). These data showed that bufalin induced rapid ROS generation within $30 \mathrm{~min}$ in the cells. 


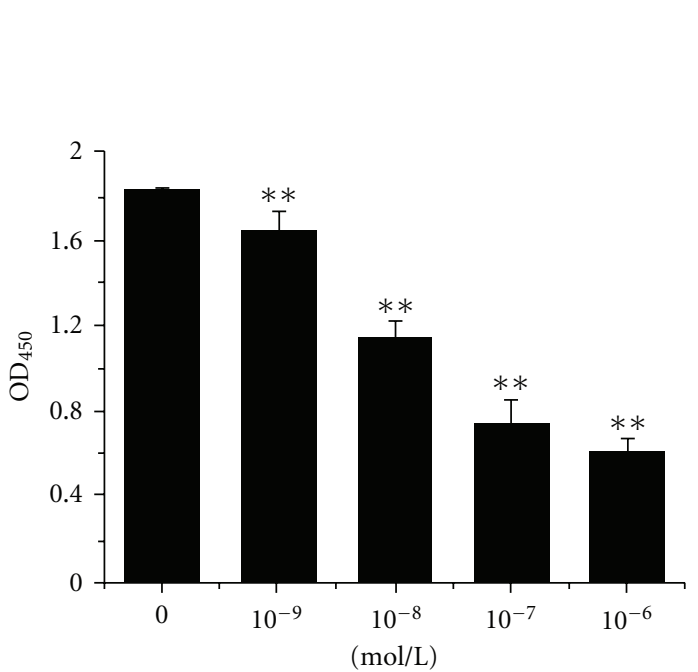

(a)

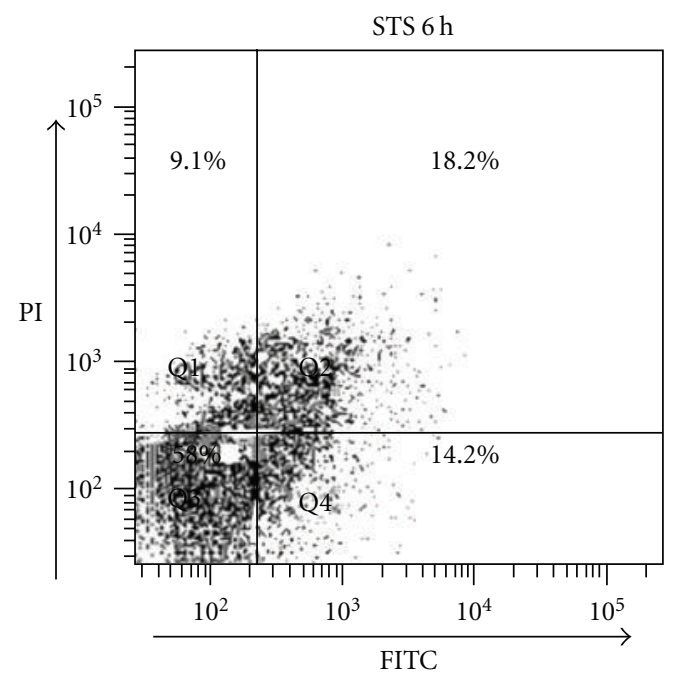

(c)

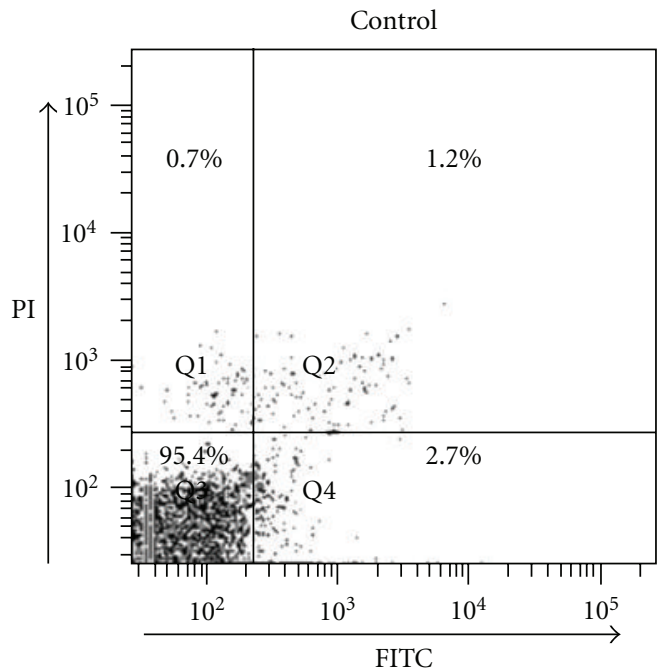

(b)

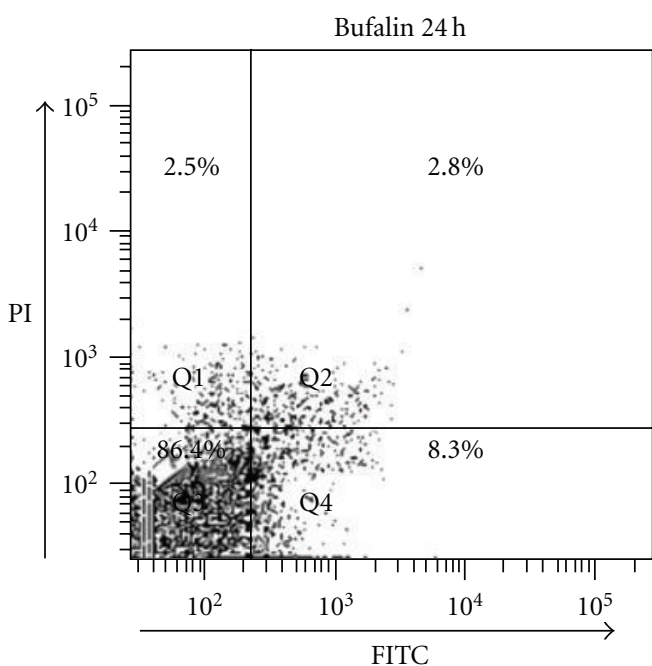

(d)

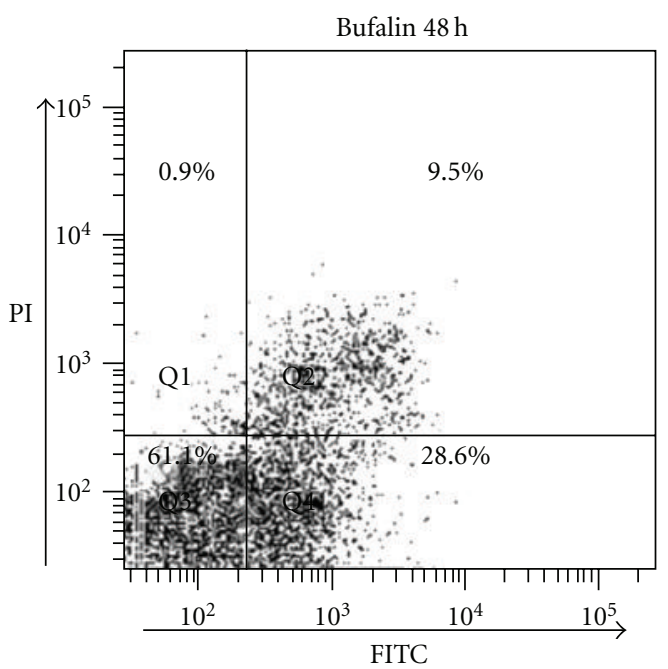

(e)

Figure 1: Bufalin-induced cell apoptosis. (a) Inhibition of bufalin on the cell viability at $48 \mathrm{~h}$ after bufalin treatment. Cell viability was measured by the CCK-8 assay. ${ }^{* *} P<.05$, compared with control. FCM analysis of apoptosis by annexin V/PI staining for control (b), treatment with STS (C), and treatment with bufalin for $24 \mathrm{~h} \mathrm{(d)} \mathrm{or} 48 \mathrm{~h}(\mathrm{e})$. 


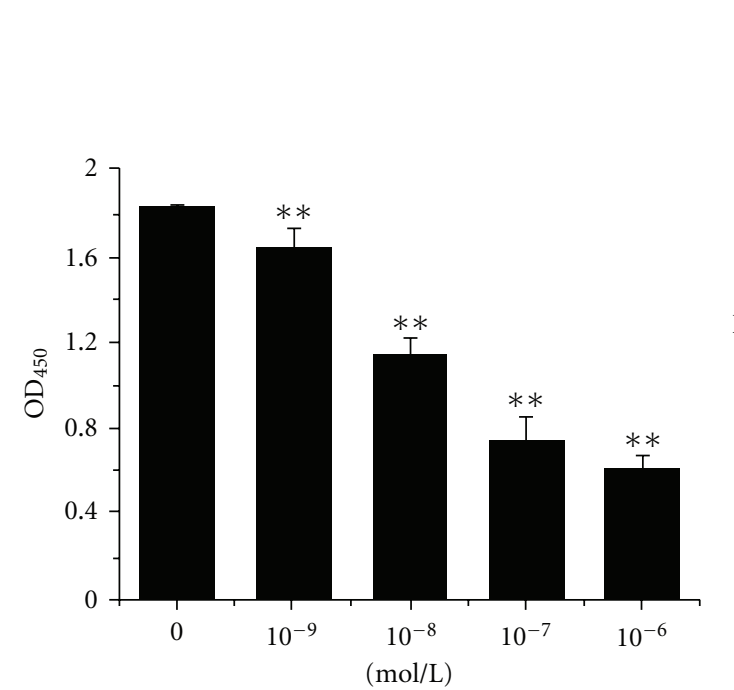

(a)

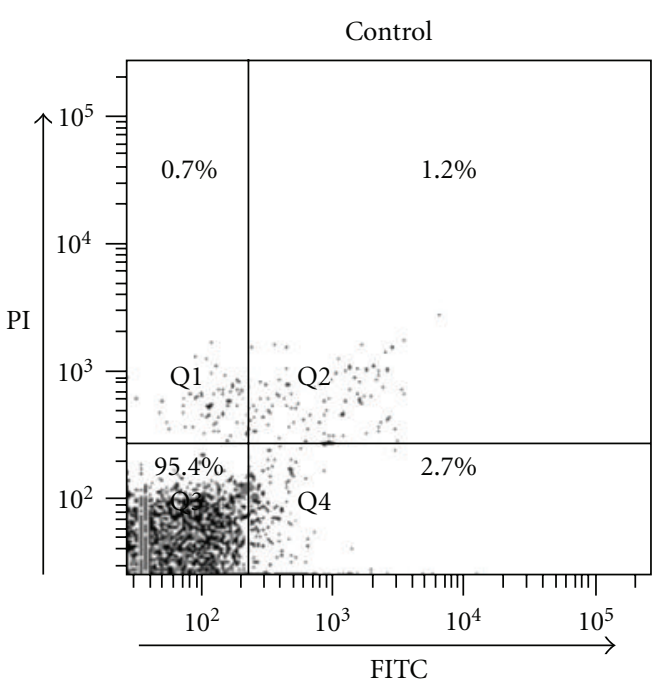

(b)

FIGURE 2: Dynamics of ROS production during bufalin-induced apoptosis. (a) Fluorescence images of DCF inside living cells after treatment with bufalin in the presence or absence of NAC. Scale bar: $10 \mu \mathrm{m}$. (b) The dynamical progress of ROS generation corresponding to (A). Data were obtained from three independent experiments.

We next sought to determine whether ROS were involved in bufalin-induced cell apoptosis. Compared with the control, over $50 \%$ of cells lost viability at $48 \mathrm{~h}$ after treatment with bufalin alone, whereas pretreatment with NAC markedly eliminated the inhibition of bufalin on cell viability (Figure 3(a)). These results showed that bufalin induced apoptosis via ROS-dependent pathway. The results were further confirmed by cellular morphology using Hoechst 33258 staining (Figure 3(b)). The cells treated with bufalin displayed cell shrinkage, chromatin condensation (arrows indicate the nuclei of apoptotic cells) and margination in the nucleus, which were markedly prevented by treatment with NAC (Figure 3(b)). Percentage of apoptotic cells from Hoechst 33258 staining images at $24 \mathrm{~h}$ after bufalin treatment and $48 \mathrm{~h}$ after bufalin treatment in the absence or presence of NAC are shown in Figure 3(c). Collectively, these results showed that ROS were involved in bufalin-induced cell apoptosis. In addition, pretreatment with z-VAD-fmk showed significant protection to bufalin-treated cells, indicating that caspase family were involved in bufalin-induced apoptosis (Figure 3(a)).

\subsection{ROS Involvement in Bufalin-induced Bax Translocation.} In some models of mitochondrial-dependent apoptosis, ROS act upstream to cause the activation of Bax or Bak [27]. To explore whether ROS acted upstream of Bax activation in bufalin-induced apoptosis, we used CFM to image the Bax distribution in living cells expressing GFP-Bax after STS or bufalin treatment in the presence or absence of NAC (Figure 4(a)). STS treatment resulted in time-dependent Bax translocation (Figures 4(a) and 4(b)), and bufalin also induced time-dependent Bax translocation, which was markedly inhibited by NAC (Figures 4(a) and 4(c)). The data were collected from 400 to 500 cells per treatment in 15-20 randomly selected image frames from at least three independent experiments. These results implied that ROS mediated the bufalin-induced Bax translocation and apoptosis.

\subsection{Bufalin-Induced ROS-Dependent Mitochondrial Dysfunc-} tion. Since mitochondria play an important role in the apoptotic process, we next evaluated whether bufalin triggered mitochondrial events of apoptosis. One of the mitochondrial events is the ultrastructural changes. Treating the cells with bufalin for $48 \mathrm{~h}$ influenced the morphology of mitochondria, which were significantly eliminated by NAC (Figure 5(a)). We also found out that the size of mitochondria gradually increased from $0.65 \pm 0.09$ to $0.93 \pm 0.23 \mu \mathrm{m}$ after bufalin treatment compared with the control (Figure 5(b)), while the size of mitochondria under combined treatment with bufalin and NAC was $0.68 \pm 0.08 \mu \mathrm{m}$. Another important mitochondrial event related to apoptosis is the permeability change, which is associated with a drop in mitochondrial membrane potential $\left(\Delta \Psi_{m}\right)$. We used FCM to detect the loss of $\Delta \Psi_{m}$ by measuring the percentage of cells with Rho123 fluorescence under various treatments (Figure 5(c)). The percentage of cells with Rho123 fluorescence after treatment with bufalin alone for $0,12,24$ or $48 \mathrm{~h}$ were $7.6 \%, 12.1 \%$, $14.8 \%$ or $41.8 \%$, respectively, with the latter reducing to $21.3 \%$ in the presence of NAC (Figure 5(c)). These results indicated that bufalin induced a time- and ROS-dependent loss of $\Delta \Psi_{m}$.

In addition, we monitored the dynamics of cytochrome $c$ release events inside single living cell co-expressing Cytc-GFP and DsRed-mito using time-lapse CFM (LSM510Meta, Zeiss, Germany). Our data showed that cytochrome $c$ was not released from mitochondria to cytosol under bufalin treatment for $24 \mathrm{~h}$, implying that cytochrome $c$ was not involved in bufalin-induced apoptosis. We also detect the 


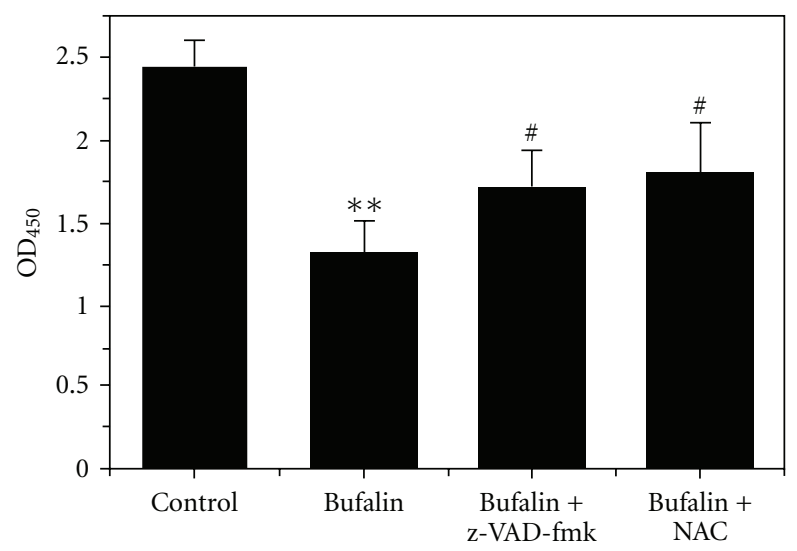

(a)
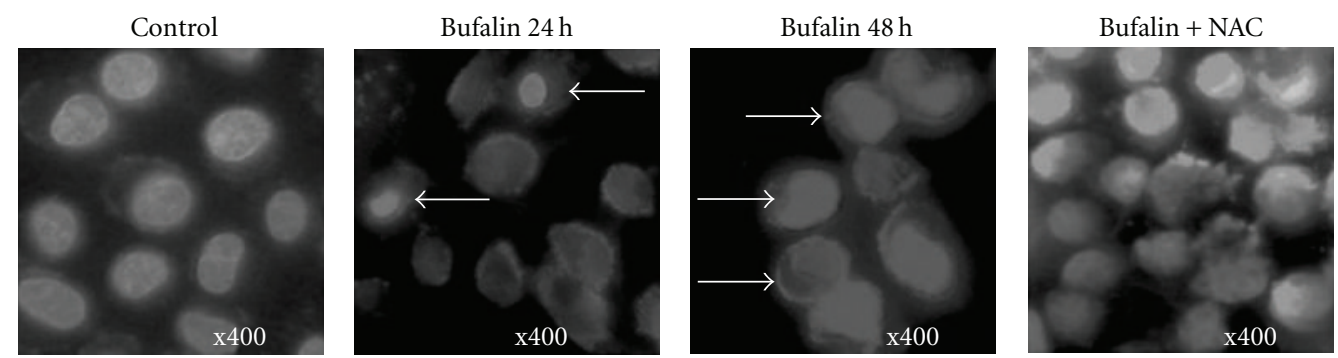

(b)

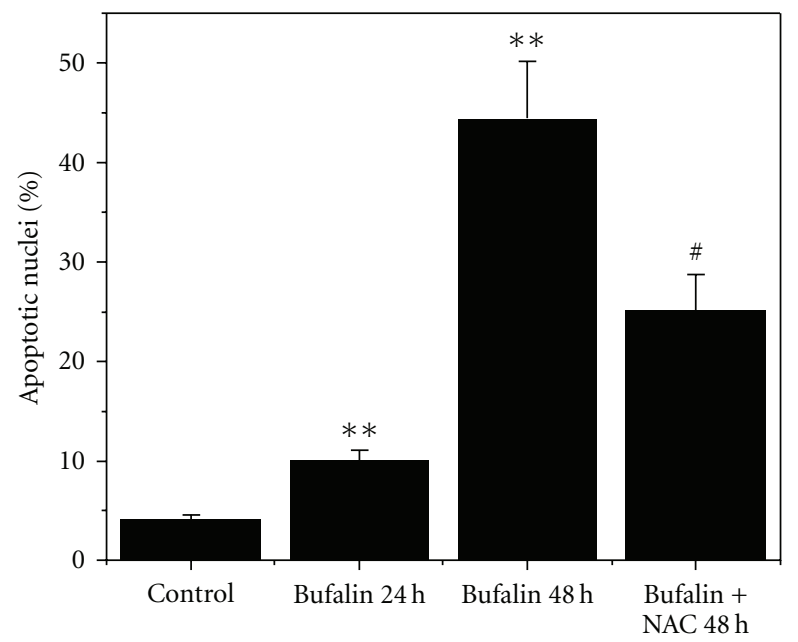

(c)

FIgURE 3: ROS involvement in bufalin-induced apoptosis. (a) Inhibition of z-VAD-fmk or NAC on the cytotoxicity of bufalin. (b) Typical fluorescence images of cells stained with Hoechst 33258. Magnification $\times 400$. (c) Percentage of apoptotic cells according to Hoechst 33258 staining images. Each column represents the average obtained from three independent experiments. ${ }^{* *} P<.05$, compared with control. ${ }^{\#} P$ $<.05$, compared with treatment with bufalin alone.

caspase- 9 activation during bufalin-induced apoptosis inside living cells expressing SCAT 9 plas-mid using FRET acceptor photobleaching and emission spectral analysis as we did in previous studies $[8,26]$. Our data showed that caspase-9 was not activated under bufalin treatment.

\subsection{Bufalin-Induced ROS-mediated Caspase-3 Activation.} Caspase- 3 activation was examined during bufalin-induced apoptosis in living cells expressed stably with SCAT3 by monitoring the fluorescence emission spectra of SCAT3, which had been used in our previous study [26]. Bimodal emission peaks at 480 and $524 \mathrm{~nm}$ were observed with 430-nm excitation. The strong peak at $524 \mathrm{~nm}$ of Venus was due to the FRET between ECFP and Venus in control cells (Figure 6(a)). STS activated caspase-3, which cleaved SCAT3, and then led to a significant decrease at the peak of $524 \mathrm{~nm}$ and a corresponding increase at the peak of $480 \mathrm{~nm}$, which was markedly inhibited by z-VAD-fmk (Figure 6(a)). 


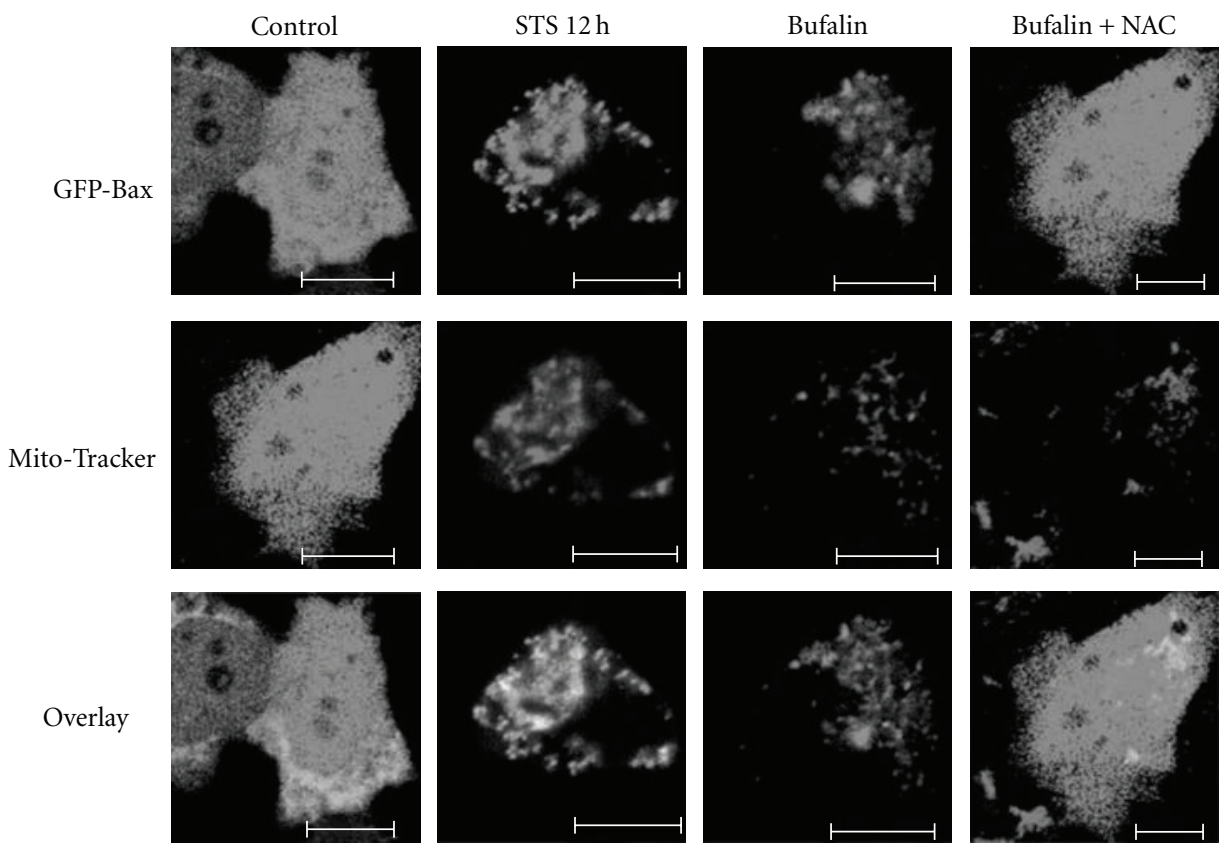

(a)

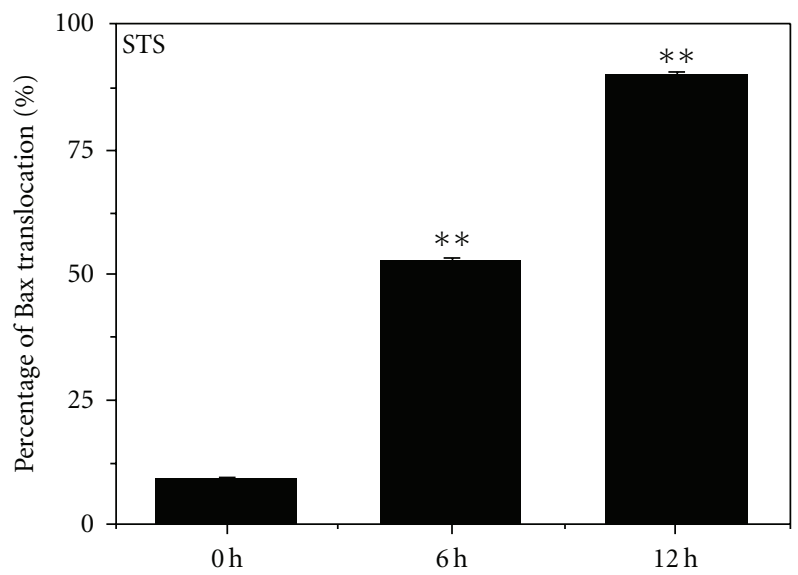

(b)

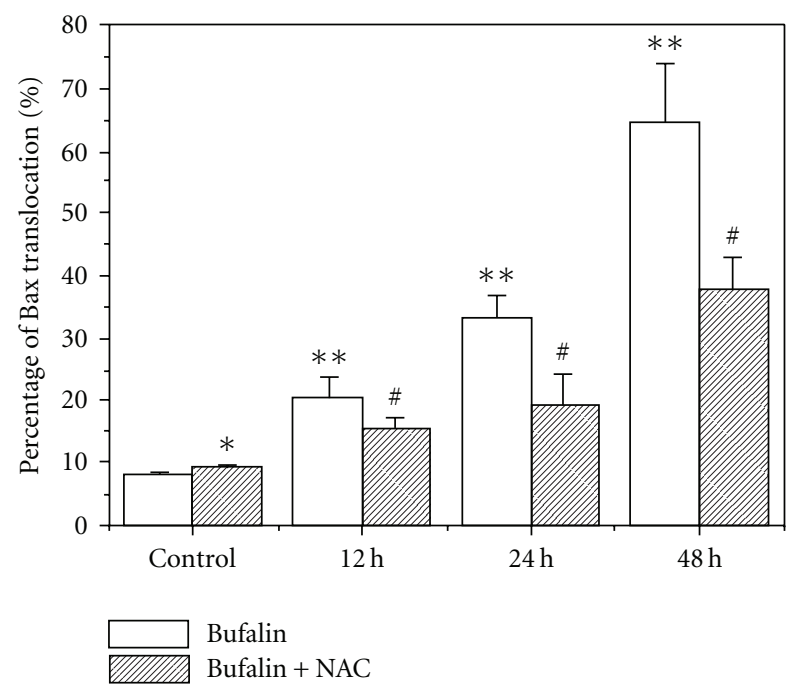

(c)

Figure 4: Bufalin induced ROS-dependent Bax translocation. (a) Typical fluorescence images of cells expressing GFP-Bax after different treatments. Mitotracker was used to label mitochondria. Scale bar: $10 \mu \mathrm{m}$. (b) Percentage of cells with Bax translocation at 0,6 or $12 \mathrm{~h}$ after STS treatment. (c) Percentage of cells with Bax translocation at 0,12, 24 or $48 \mathrm{~h}$ after bufalin treatment in the absence or presence of NAC. Data were collected in 400-500 cells per treatment in 15-20 randomly selected image frames and from three independent experiments $(n$ $=3$ ). Results were presented as mean $\pm \mathrm{SD} .{ }^{*} P>.05$, compared with control. ${ }^{* *} P<.05$, compared with control. ${ }^{\#} P<.05$, compared with treatment with bufalin alone.

Similarly, the peak at $524 \mathrm{~nm}$ completely disappeared at $48 \mathrm{~h}$ after bufalin treatment, which was also inhibited by z-VADfmk (Figure 6(b)), implying that bufalin activated caspase3. In order to verify whether ROS were involved in the bufalin-induced caspase- 3 activation, we also measured the emission spectra of SCAT3 after combined treatment with bufalin and NAC. NAC significantly attenuated the decrcease at the peak of $524 \mathrm{~nm}$ compared with bufalin treatment alone
(Figure 6(c)), indicating ROS were involved in the bufalininduced caspase- 3 activation.

Western blot analysis was performed to further confirm bufalin-induced ROS-dependent caspase-3 activation. Caspase- 3 was primarily present as the $35-\mathrm{kDa}$ pro-form for the untreated cells (Figure 6(d), lane 1). Following exposure to STS for $12 \mathrm{~h}$, caspase- 3 activation was detected by the loss of pro-form and the appearance of processed caspase- 3 , 

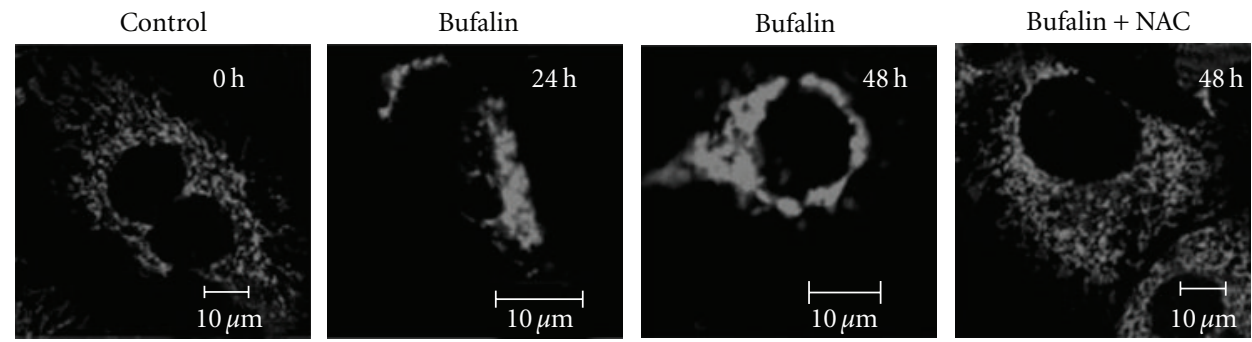

(a)

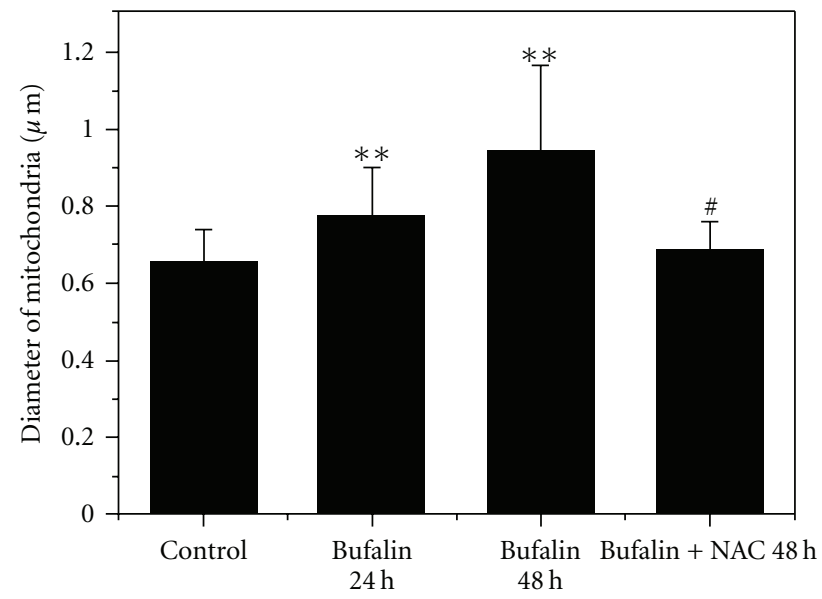

(b)
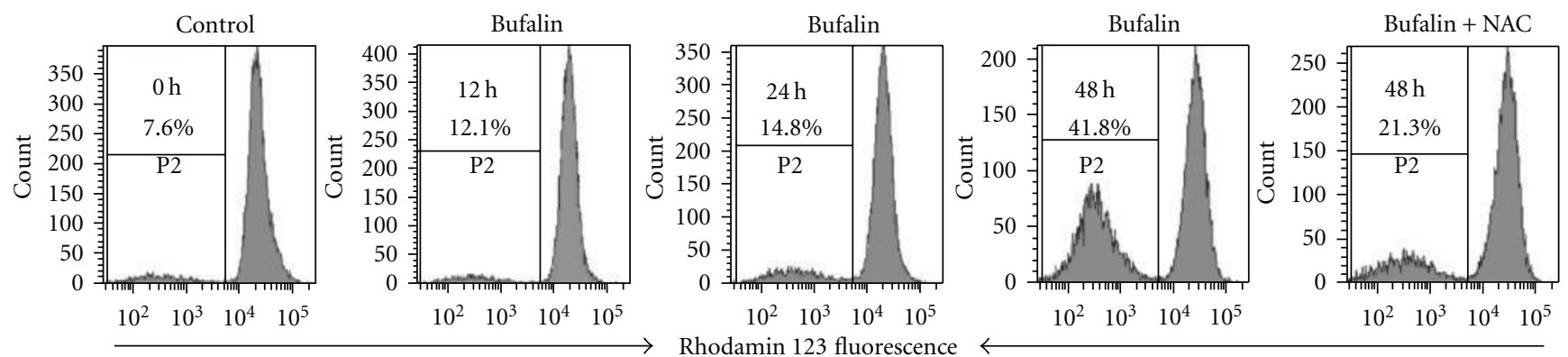

(c)

Figure 5: Mitochondrial dysfunction induced by bufalin. (a) Typical fluorescent images of mitochondria under different treatments. The mitochondria in bufalin-treated cells were obviously swollen. Scale bar: $10 \mu \mathrm{m}$. (b) Quantification of mitochondrial width under different treatments. ${ }^{* *} P<.05$, compared with control. ${ }^{*} P<.05$, compared with treatment with bufalin alone. (c) FCM analysis of mitochondrial membrane potential $\left(\Delta \Psi_{m}\right)$ loss induced by bufalin. The proportions of cells with reduced Rho123 fluorescence were shown. Experiments were performed in triplicate with similar results.

p17 fragment from cleavage of caspase-3 (Figure 6(d), lane 4). Treatment with bufalin for $48 \mathrm{~h}$ showed the same result (Figure 6(d) lane 2). In addition, bufalin-induced caspase-3 activation was blocked by combined treatment with bufalin and NAC (Figure 6(d), lane 3).

We next used AFC to further detect caspase-3 activation during bufalin-induced apoptosis. AFC release is an indicator of caspase-3 activation [28]. The level of caspase enzymatic activity in the cell lysate is directly proportional to the fluorescence signal detected with a fluorescent microplate reader. As shown in Figure 6(e), after incubation with AcDEVD-AFC for $1 \mathrm{~h}$, bufalin treatment induced nearly a 3 fold increase in caspase-3 activity compared with control.
In contrast, the cleavage of Ac-DEVD-AFC in response to caspase- 3 activation was blocked by combined treatment with bufalin and NAC (Figure 6(e)).

Taken together, these results demonstrated that bufalin induced ROS-mediated caspase- 3 activation.

\section{Discussion}

In this study, we for the first time used fluorescence techniques and the time-lapse CFM to reveal that bufalin induced apoptosis via ROS-dependent mitochondrial pathway in living ASTC-a-1 cells. Bufalin-induced ROS production reached the maximum within $30 \mathrm{~min}$. Furthermore, ROS 


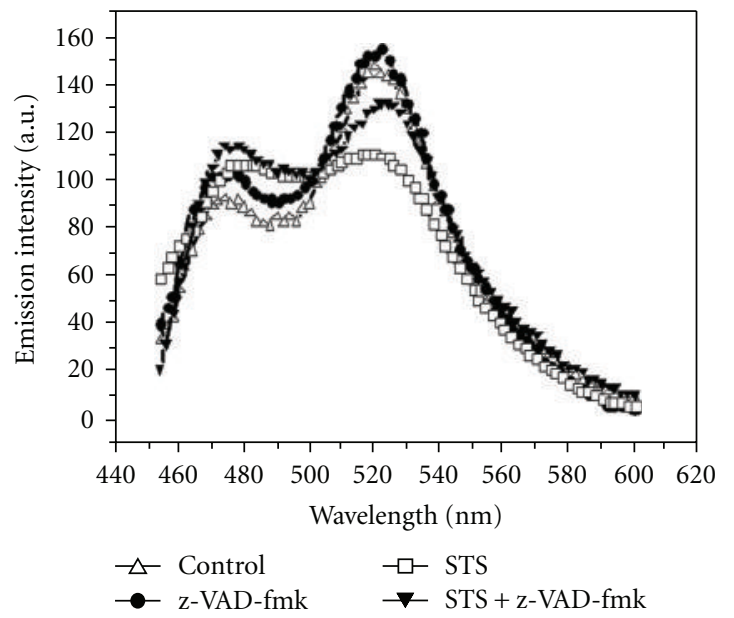

(a)

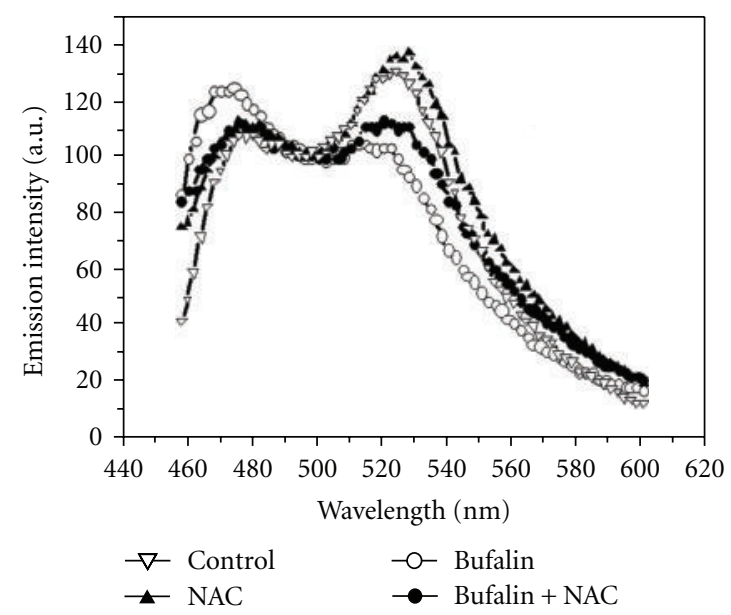

(c)

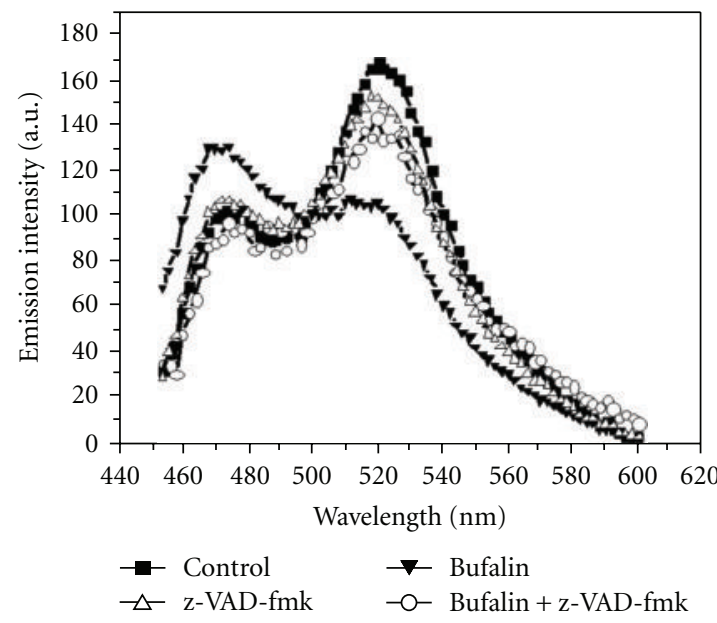

(b)

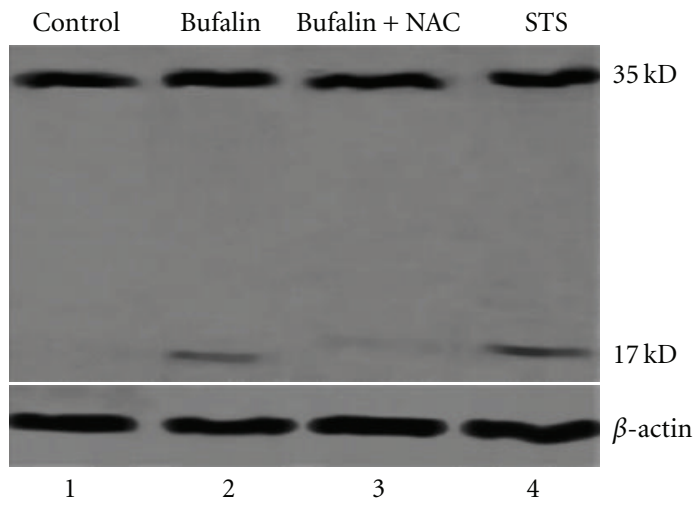

(d)

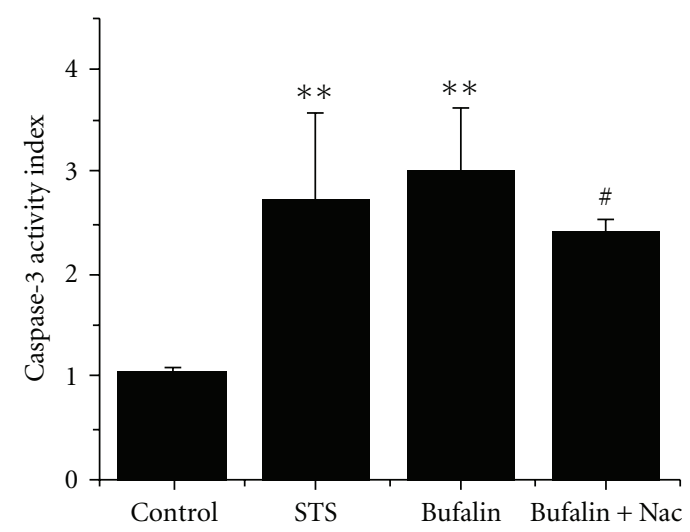

(e)

FIGURE 6: Caspase-3 activation induced by bufalin via ROS-dependent pathway. (a) STS-induced caspase-3 activation. (b) Bufalin-induced caspase-3 activation. (c) ROS-mediated bufalin-induced caspase-3 activation. (d) Western blot assay of ROS-mediated caspase-3 activation induced by bufalin. (e) Fluorometric assay of ROS-mediated caspase- 3 activation induced by bufalin. ${ }^{* *} P<.05$, compared with control; ${ }^{\#} P$ $<.05$, compared with treatment with bufalin alone. 


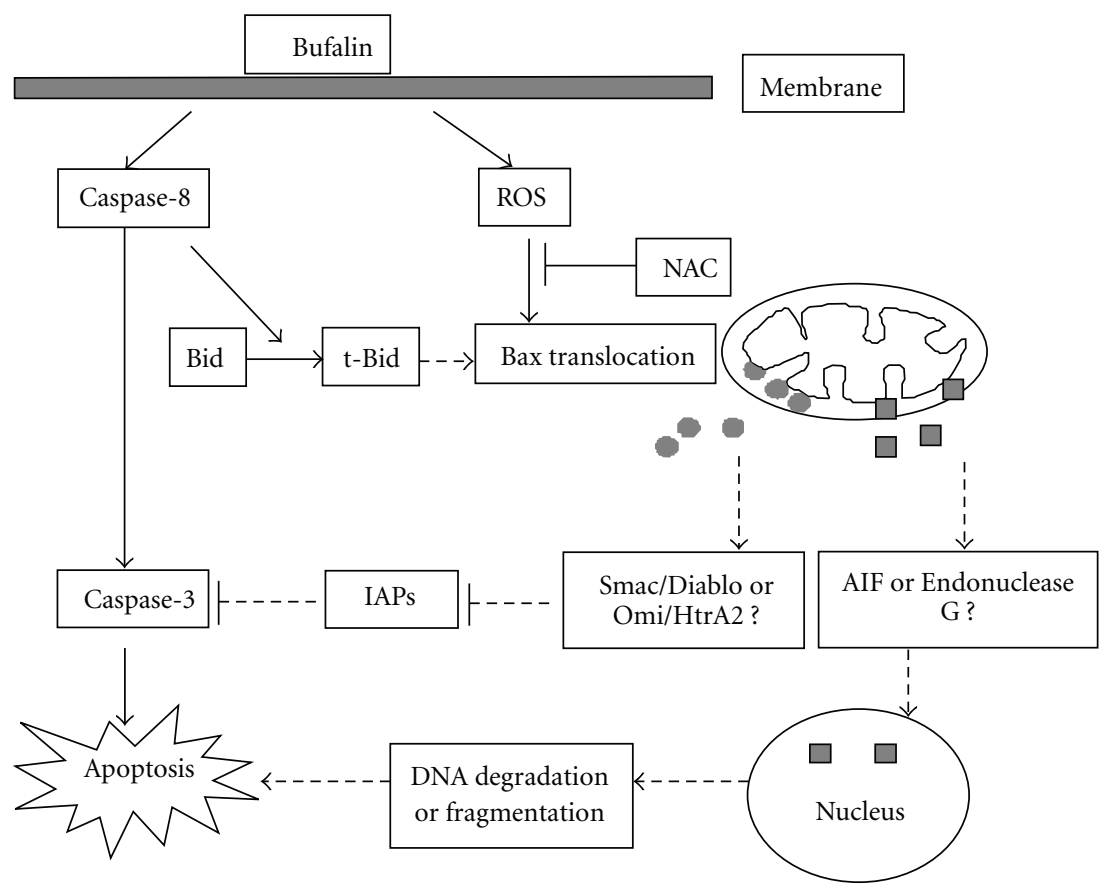

FIGURE 7: Schematic representation of the bufalin-induced apoptotic pathway in ASTC-a-1 cells. Once engaged by bufalin, two signal pathways are activated. One is the death receptor-mediated pathway and the other is the mitochondrion pathway. Omi/HtrA2: high temperature requirement protein A2; Smac/Diablo: second mitochondria derived activator of caspase/direct inhibitor of an apoptosisbinding protein; AIF: apoptosis inducing factor.

mediated Bax translocation and the loss of mitochondrial potential. It has important clinical significance to guide the treatment for lung cancers.

Our results showed that bufalin-induced ROS production was not just generated from mitochondria. Bufalin induced ROS generation throughout the whole cells (Figure 2(a)), which was similar to the results of ROS involvement in lung cancer A549 cells and prostate cell lines apoptosis [14, 22]. However, a number of other reports showed that bufalin inhibited $\mathrm{Na}^{+}-\mathrm{K}^{+}$-ATPase $[20,23,24]$, which increased mitochondrial production of ROS [24].

ROS may act upstream of mitochondrial membrane permeabilization and mediate mitochondrial dysfunction in bufalin-induced apoptosis. ROS generation has been reported to occur following mitochondrial outer membrane permeabilization [27]. However, our results showed that ROS acted upstream of the bufalin-induced mitochondria dysfunctions and mitochondrial network dismantling (Figure 5). ROS may promote MPT by causing the oxidation of thiol groups on the adenine nucleotide translocator, which is believed to form part of the MPT pore [29].

One point worthy to be mentioned is that not all Bax translocate to mitochondria in response to bufalin. Some Bax clusters do not co-localize with mitochondria. Instead, they were associated with one or two round mitochondrias (Figure 5(a)). STS treatment led to the accumulation or targeting of Bax to mitochondria as shown in Figure 5(a), which was in accordance with previous studies [30]. It indicates that the mechanism of bufalin-induced Bax translocation is different from that of STS. STS induces Bax insertion into mitochondria membranes [30]. However, bufalin induces Bax translocation to the surface or around the mitochondria.

To investigate which initiator caspase is involved in this apoptosis process, we detected whether caspase- 8 was involved in bufalin-induced apoptosis inside living cells expressing the FRET-Bid plasmid using FRET acceptor photobleaching and emission spectral analysis as we did in previous studies $[8,26]$. Our data showed that caspase- 8 was activated in bufalin-induced apoptosis. Caspase- 3 plays an important role in drug-induced cytotoxic apoptosis in NSCLC [31]. Here, we demonstrated that caspase-3 was activated in a ROS-dependent pathway after bufalin treatment (Figure 6). However, caspase-3 was still activated partially if eliminating ROS (Figures 6(c) and 6(e)), implying that there may be some alternative pathways to activate caspase- 3 in addition to a ROS-dependent caspase-3 activation pathway in response to bufalin treatment.

According to the experimental data, we summarize the signaling pathways (Figure 7) related to bufalin-induced apoptosis in ASTC-a-1 cells. Once engaged by bufalin, two signal pathways are activated. One is the extrinsic pathway, in which bufalin induced caspase- 8 activation, which subsequently activated caspase- 8 directly activates caspase- 3 . The other is the intrinsic pathway, in which bufalin induced ROS-dependent Bax translocation, loss of mitochondrial membrane potential and caspase- 3 activation. Cytochrome $c$ release from the mitochondria and caspase- 9 activation were not observed after bufalin treatment, suggesting that 
cytochrome $c$ and caspase-9 were not involved in bufalininduced apoptosis. However, NAC, a ROS scavenger, can partially inhibit caspase- 3 activation induced by bufalin (Figures 3(a)-3(c) ), implying that Smac/Diablo or Omi/HtrA2 released from the mitochondria antagonize the inhibitors of apoptosis (IAPs) and contribute to activation of caspase-3 [32]. z-VAD-fmk, a broad spectrum caspases inhibitor, did not completely inhibit cell death and caspase-3 activation (Figures 3(b) and 6(b)), indicating that caspase-independent apoptotic pathways may be involved in the bufalin-induced apoptosis, in which AIF or endonuclease G may play a partial role. Bufalin would induce AIF or endonuclease G release from mitochondria to cytosol and translocate to nucleus, causing DNA fragmentation and apoptosis. These imply that bufalin triggers the signaling to induce cell apoptosis via both death receptor-mediated and mitochondrial pathways. We would like to further investigate how other signaling pathways are involved in the bufalin-induced human lung cancer cell apoptosis. We hope our findings on anticancer effects of bufalin will help us improve medical treatment and prevention of human lung cancer.

\section{Funding}

National Natural Science Foundation of China (Grant No. 30670507); the Natural Science Foundation of Guangdong Province (F051001); 'Shuguang Scholor' (Grant No. 07SG05) of Education Commission; 'Leading Academic Development Project' (Grant No. B109) of the Science \& Technology Commission of Shanghai Municipality.

\section{References}

[1] S. Elmore, "Apoptosis: a review of programmed cell death," Toxicologic Pathology, vol. 35, no. 4, pp. 495-516, 2007.

[2] S. Gupta, "Molecular steps of death receptor and mitochondrial pathways of apoptosis," Life Sciences, vol. 69, no. 25-26, pp. 2957-2964, 2001.

[3] M. Rehm, H. Düßmann, R. U. Jänicke, J. M. Tavaré, D. Kögel, and J. H. M. Prehn, "Single-cell fluorescence resonance energy transfer analysis demonstrates that caspase activation during apoptosis is a rapid process: role of caspase-3," Journal of Biological Chemistry, vol. 277, no. 27, pp. 24506-24514, 2002.

[4] A. Nechushtan, C. L. Smith, I. Lamensdorf, S.-H. Yoon, and R. J. Youle, "Bax and Bak coalesce into novel mitochondriaassociated clusters during apoptosis," Journal of Cell Biology, vol. 153, no. 6, pp. 1265-1276, 2001.

[5] Å. B. Gustafsson and R. A. Gottlieb, "Bcl-2 family members and apoptosis, taken to heart," American Journal of Physiology, vol. 292, no. 1, pp. C45-C51, 2007.

[6] L. Zhang, D. Xing, L. Liu, X. Gao, and M. Chen, "TNF $\alpha$ induces apoptosis through JNK/Bax-dependent pathway in differentiated, but not naïve PC12 cells," Cell Cycle, vol. 6, no. 12, pp. 1479-1486, 2007.

[7] L. Zhang, D. Xing, and M. Chen, "BimL displacing Bcl-xL promotes Bax translocation during TNF $\alpha$-induced apoptosis," Apoptosis, vol. 13, no. 7, pp. 950-958, 2008.

[8] Y. Wu, D. Xing, W. R. Chen, and X. Wang, "Bid is not required for Bax translocation during UV-induced apoptosis," Cellular Signalling, vol. 19, no. 12, pp. 2468-2478, 2007.
[9] J. Zhao, T. Liu, L. Ma et al., "Antioxidant and preventive effects of extract from Nymphaea candida flower on in vitro immunological liver injury of rat primary hepatocyte cultures," Evidence-Based Complementary and Alternative Medicine. In press.

[10] J. L. Farber, M. E. Kyle, and J. B. Coleman, "Mechanisms of cell injury by activated oxygen species," Laboratory Investigation, vol. 62, no. 6, pp. 670-679, 1990.

[11] H. W. Kim, S. J. Cho, B. Y. Kim, S. I. Cho, and Y. K. Kim, "Pogostemon cablin as ROS scavenger in oxidant-induced cell death of human neuroglioma cells," Evidence-Based Complementary and Alternative Medicine, vol. 7, no. 2, pp. 239-247, 2008.

[12] S. V. Kalivendi, S. Kotamraju, H. Zhao, J. Joseph, and B. Kalyanaraman, "Doxorubicin-induced apoptosis is associated with increased transcription of endothelial nitric-oxide synthase: effect of antiapoptotic antioxidants and calcium," Journal of Biological Chemistry, vol. 276, no. 50, pp. 47266-47276, 2001.

[13] E. Gottlieb, M. G. Vander Heiden, and C. B. Thompson, "Bcl$\mathrm{x}(\mathrm{L})$ prevents the initial decrease in mitochondrial membrane potential and subsequent reactive oxygen species production during tumor necrosis factor alpha-induced apoptosis," Molecular and Cellular Biology, vol. 20, pp. 5680-5689, 2000.

[14] Y. H. Han, S. Z. Kim, S. H. Kim, and W. H. Park, "Induction of apoptosis in arsenic trioxide-treated lung cancer A549 cells by buthionine sulfoximine," Molecules and Cells, vol. 26, no. 2, pp. 158-164, 2008.

[15] Y. K. Ki, H. A. Jin, and G. C. Hyae, "Apoptotic action of PPAR $\gamma$ activation in human non-small cell lung cancer is mediated via proline oxidase-induced ROS formation," Molecular Pharmacology, vol. 107, pp. 35584-35631, 2007.

[16] F. A. Shepherd, "Angiogenesis inhibitors in the treatment of lung cancer," Lung Cancer, vol. 34, no. 3, pp. 81-89, 2001.

[17] J. H. Schiller, "Current standards of care in small-cell and nonsmall-cell lung cancer," Oncology, vol. 61, no. 1, pp. 3-13, 2001.

[18] H. K. Weir, M. J. Thun, B. F. Hankey et al., "Annual report to the nation on the status of cancer, 1975-2000, featuring the uses of surveillance data for cancer prevention and control," Journal of the National Cancer Institute, vol. 95, no. 17, pp. 1276-1299, 2003.

[19] L. Krenn and B. Kopp, "Bufadienolides from animal and plant sources,” Phytochemistry, vol. 48, no. 1, pp. 1-29, 1998.

[20] S. Numazawa, M.-A. Shinoki, H. Ito, T. Yoshida, and Y. Kuroiwa, "Involvement of $\mathrm{Na}^{+}, \mathrm{K}^{+}$-ATPase inhibition in $\mathrm{K} 562$ cell differentiation induced by bufalin," Journal of Cellular Physiology, vol. 160, no. 1, pp. 113-120, 1994.

[21] K.-Q. Han, G. Huang, W. Gu, Y.-H. Su, X.-Q. Huang, and C.-Q. Ling, "Anti-tumor activities and apoptosis-regulated mechanisms of bufalin on the orthotopic transplantation tumor model of human hepatocellular carcinoma in nude mice," World Journal of Gastroenterology, vol. 13, no. 24, pp. 3374-3379, 2007.

[22] C.-H. Yu, S.-F. Kan, H.-F. Pu, E. Jea Chien, and P. S. Wang, "Apoptotic signaling in bufalin- and cinobufagin-treated androgen-dependent and -independent human prostate cancer cells," Cancer Science, vol. 99, no. 12, pp. 2467-2476, 2008.

[23] N. Kawazoe, T. Aiuchi, Y. Masuda, S. Nakajo, and K. Nakay, "Induction of apoptosis by bufalin in human tumor cells is associated with a change of intracellular concentration of $\mathrm{Na}^{+}$ Ions," The Journal of Biochemistry, vol. 126, pp. 278-286, 1999.

[24] Z. Xie and T. Cai, " $\mathrm{Na}^{+}-\mathrm{K}^{+}$- aTPase-mediated signal transduction: from protein interaction to cellular function," $\mathrm{Mol}$ Interv, vol. 3, no. 3, pp. 157-168, 2003. 
[25] K. Takemoto, T. Nagai, A. Miyawaki, and M. Miura, "Spatiotemporal activation of caspase revealed by indicator that is insensitive to environmental effects," Journal of Cell Biology, vol. 160, no. 2, pp. 235-243, 2003.

[26] Y. Wu, D. Xing, S. Luo, Y. Tang, and Q. Chen, "Detection of caspase- 3 activation in single cells by fluorescence resonance energy transfer during photodynamic therapy induced apoptosis," Cancer Letters, vol. 235, no. 2, pp. 239-247, 2006.

[27] L. J. Buccellato, M. Tso, O. I. Akinci, N. S. Chandel, and G. R. S. Budinger, "Reactive oxygen species are required for hyperoxiainduced Bax activation and cell death in alveolar epithelial cells," Journal of Biological Chemistry, vol. 279, no. 8, pp. 6753 6760, 2004.

[28] J. M. Angelastro, N. Y. Moon, D. X. Liu, A.-S. Yang, L. A. Greene, and T. F. Franke, "Characterization of a novel isoform of caspase-9 that inhibits apoptosis," Journal of Biological Chemistry, vol. 276, no. 15, pp. 12190-12200, 2001.

[29] H. L. Vieira, A. S. Belzacq, D. Haouzi, F. Bernassola, I. Cohen, E. Jacotot et al., "The adenine nucleotide translocator: a target of nitric oxide, peroxynitrite, and 4-hydroxynonenal," Oncogene, vol. 20, pp. 4305-4316, 2001.

[30] H. L. Tang, A.-H. P. Le, and H. L. Lung, "The increase in mitochondrial association with actin precedes Bax translocation in apoptosis," Biochemical Journal, vol. 396, no. 1, pp. 1-5, 2006.

[31] T. L. Weigel, M. T. Lotze, P. K. Kim, A. A. Amoscato, J. D. Luketich, and C. Odoux, "Paclitaxel-induced apoptosis in non-small cell lung cancer cell lines is associated with increased caspase-3 activity," Journal of Thoracic and Cardiovascular Surgery, vol. 119, no. 4, pp. 795-803, 2000.

[32] C. Wiart, "Goniothalamus species: a source of drugs for the treatment of cancers and bacterial infections?" Evidence-Based Complementary and Alternative Medicine, vol. 4, no. 3, pp. 299-311, 2007. 


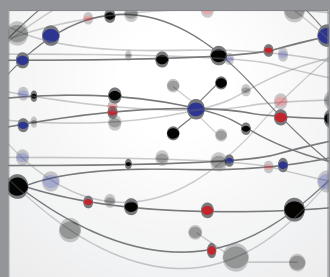

The Scientific World Journal
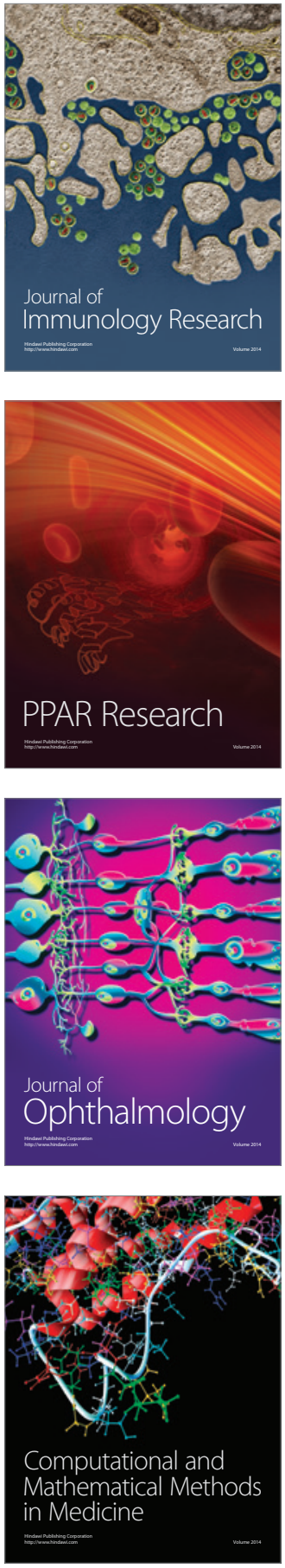

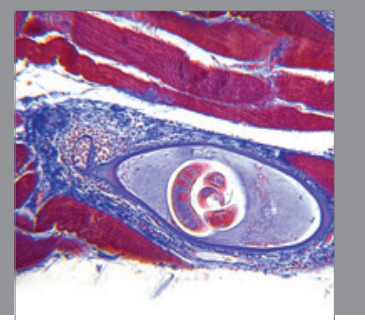

Gastroenterology

Research and Practice
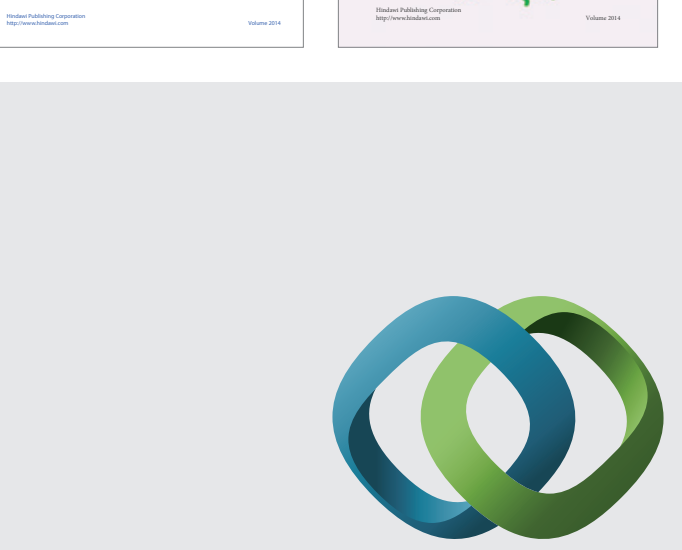

\section{Hindawi}

Submit your manuscripts at

http://www.hindawi.com
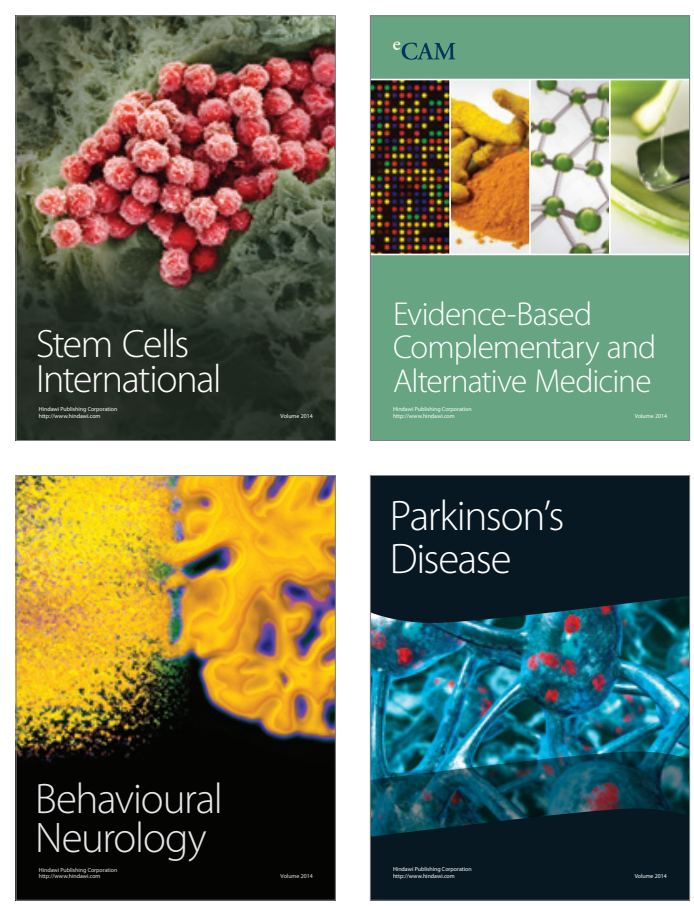

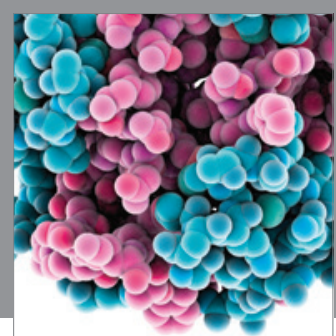

Journal of
Diabetes Research

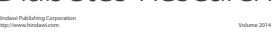

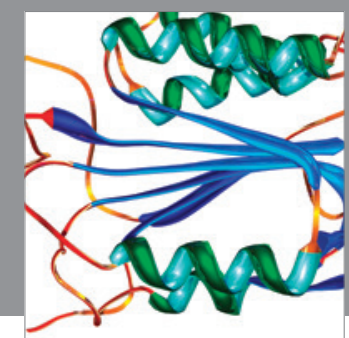

Disease Markers
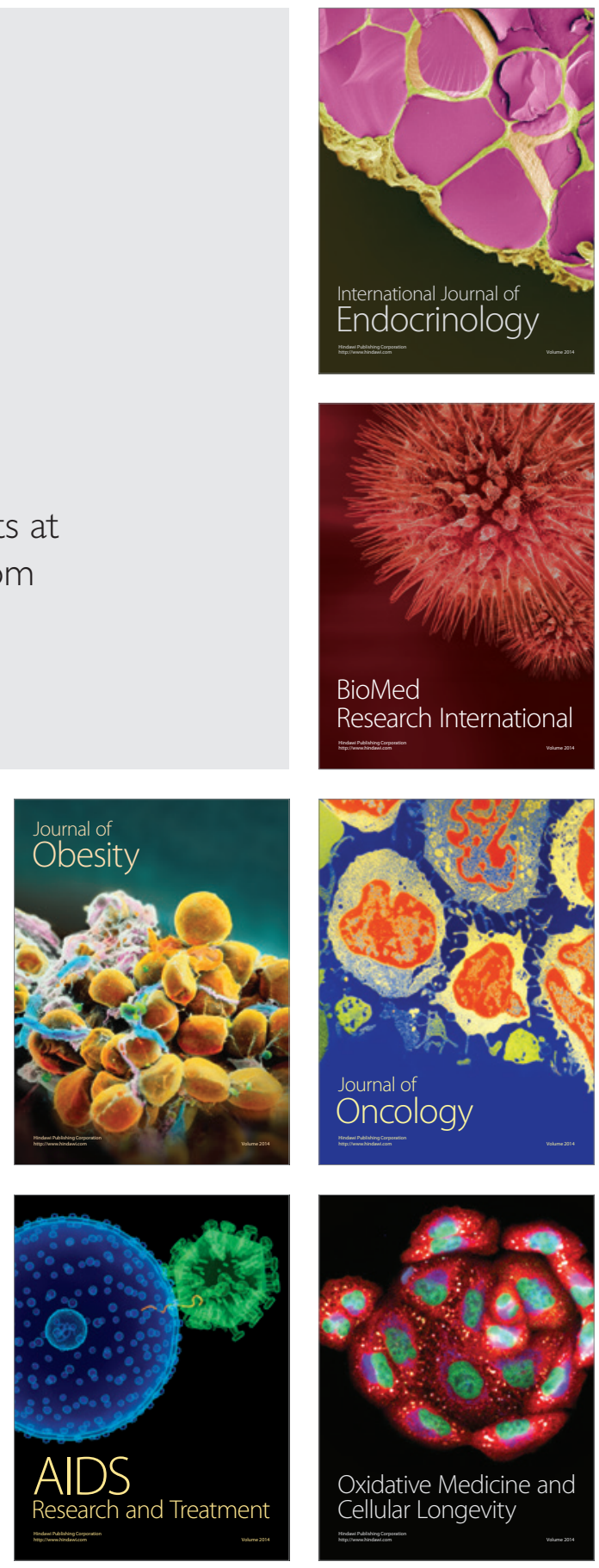